Article

\title{
Sustainability Descriptive Labels on Farmed Salmon: Do Young Educated Consumers Like It More?
}

\author{
Djin Gie Liem ${ }^{1, *(1)}$, Giovanni M. Turchini ${ }^{2}$, Uracha Wanich ${ }^{1}$ and Russell Keast ${ }^{1}$ (i) \\ 1 Centre for Advanced Sensory Science, School of Exercise and Nutrition Sciences, Deakin University, \\ 221 Burwood Highway, Burwood, VIC 3125, Australia; uwanich@deakin.edu.au (U.W.); \\ Russell.keast@deakin.edu.au (R.K.) \\ 2 School of Life and Environmental Sciences, Deakin University, Warrnambool, VIC 3280, Australia; \\ Giovanni.turchini@deakin.edu.au \\ * Correspondence: gie.liem@deakin.edu.au; Tel.: +61-03-9244-6039
}

Received: 13 May 2018; Accepted: 7 July 2018; Published: 10 July 2018

\begin{abstract}
Despite the efforts to make fish sustainable, it is largely unknown if young educated consumers' taste of fish and their willingness to pay more for fish is influenced by positively framed messages regarding sustainable farming practices. This research investigated if a positively framed description of sustainable farming opposed to positively framed descriptions of flavour, health benefits, or socially responsible farming, influences young consumers' liking, and willingness to pay for farmed salmon. Young consumers of fish $(n=119)$ randomly tasted Fresh and hot Smoked salmon and rated their liking and willingness to pay more on structured line scales. The salmon were labelled with either a description of sustainable farming practices, flavour benefits, nutrition/health benefits, socially responsible farming practices, or no descriptions. Descriptive labelling about Sustainability $(p=0.04)$, Flavour $(p=0.01)$, and Health/nutrition $(p=0.01)$ significantly increased consumers' liking of Fresh salmon compared to Fresh salmon without labelling. No such a difference was found between the social responsibility label and the sample without labels $(p=0.2)$. Participants were willing to pay more for $250 \mathrm{~g}$ of Fresh and Smoked Salmon with descriptive labels (Fresh: $\$ 9.3 \pm \$ 0.003$; Smoked: $\$ 10.1 \pm \$ 0.003$ ), than for the same Salmon without such labels (Fresh: $\$ 9.0 \pm \$ 0.06$; Smoked: $\$ 9.8 \pm \$ 0.08)(p<0.001)$. The sustainability descriptive label had no added benefit above other descriptive labels. The liking and buying intent were, for all labels and fish types, strongly correlated $(r=0.80, p<0.001)$. In conclusion, sustainability labelling is promising, but does not differentiate from other positively framed messages.
\end{abstract}

Keywords: sustainability; sensory; seafood; consumers

\section{Introduction}

Global fish consumption has rapidly increased in the past decades. The health benefits associated with fish consumption are well recognized and health organisations across the world recommend that consumers eat around 2 to 3 servings of fish per week [1,2]. Especial young consumers consume suboptimal levels of fish [3,4]. Large quantities of fish consumption, although beneficial to health, are thought to put an unsustainable strain on the current fish supply [5]. The FAO has estimated that about $31.4 \%$ of the commercialised fish stocks are overfished and biologically unsustainable. The focus on sustainable practices, including farming fish in a sustainable manner [6,7], is therefore important from an industry as well as a consumer point of view.

There is an increased focus on sustainable seafood practices, which is reflected by an increase in sustainability certifications shown on the front of the pack, which aims to inform consumers about the positive sustainability or eco-friendly profile of the product. It is estimated that there are close to 
50 different labels worldwide related to sustainability and eco-friendliness of seafood, some of those are supported by official certifications as assessed by independent organisations (see Reference [8] for review). Although some studies have suggested that information about sustainability has a positive influence on product choice $[9,10]$ and willingness to pay [11,12], other studies failed to see such an effect [13]. More importantly, to our knowledge, none of the studies which investigated the impact of sustainability information on seafood perception actually included consumers tasting the product and assessed their liking of the taste of seafood with sustainability information.

Considering that food liking is one of the most important determinants of food choice, including fish $[14,15]$, the importance to positively influence consumers' food liking and buying intentions of sustainable fish is instrumental to increase the economic viability of the aquaculture sector. Taste is determined by the food, but also by information, which is provided to consumers at the point of purchase and at the point of consumption. Previous research with a variety of commodities suggests that the liking of products can be influenced by descriptive labelling [16]. Descriptive labelling provides consumers with additional information about the product (e.g., country of origin, production methods, ingredients, health and taste benefits) and is mostly placed on the front of the food package (also referred to as "front of the pack"), to attract consumers' attention. Descriptive labelling in this context can either be a single word or phrase (e.g., made in Australia, made by high-pressure technology), or a more elaborated marketing description such as "Belgium black forest double chocolate cake [17]". A variety of studies have suggested that descriptive labels influence consumers' taste perception and buying intention. For example, descriptive labelling on wine bottles focused on the region of origin (e.g., Dakota vs. California) can increase consumers' liking of wine [18]. Descriptions about the production process of milk (e.g., long vs. short shelf life milk) can alter consumers' liking of milk, depending on consumers' beliefs about the different milk production processes [19]. Ingredient information associated with health and/or taste benefits placed on the front of packages, such as "contains soy" [20], "reduced in salt" [21,22], "low fat" [23], and labelling emphasising the exclusivity of a product (e.g., "Belgium black forest double chocolate cake" [17] or "X-ray vision carrots" [24] can alter consumers' liking of unhealthy, as well as healthy, products. In addition, logos and messages related to social responsibility, commonly seen on food products such as coffee, chocolate $[25,26]$, rice [27], as well as seafood, seem to increase consumers' willingness to buy the product [28].

Along the same line, labelling focused on sustainability can influence consumers' liking of food as shown with various commodities such as chocolate, coffee, and lamb (see Reference [16] for review). However, consumers need to understand the sustainability label [29] and feel a high involvement with sustainability [30]. For some consumers, sustainable practices concerning fish are of high importance and relevance $[10,15,16]$. However, not all consumers place a high importance on sustainability. For them, labelling focused on sustainability is less likely to influence food liking, partly because they do not see an immediate personal benefit of sustainable foods [31]. Egocentric consumers who do not feel highly connected with "sustainability" might view products labelled as "sustainable" as not benefitting them in the near future. Whereas for those who are less egocentric and those who feel a strong involvement with the welfare of others and the greater good, descriptions focused on sustainability are more likely to influence their liking of foods. It is therefore likely that descriptive labelling concerning sustainability is specifically powerful for consumers who are highly concerned and involved in sustainability [10].

Research in Western countries such as the UK, USA, and Spain, suggest that young highly educated adults show a positive attitude towards sustainability [32] and are concerned about sustainability $[33,34]$. Research specifically focused on fish with a sustainable label suggests that those who buy fish with a sustainability label are mainly either young singles or families with older aged children living at home [35]. Several studies suggest that the sustainability of fish is valued by consumers as evidenced by the increased preference for seafood products with a sustainability label [9], but the influence of sustainability-related information on young educated consumers' liking of the taste of seafood is underexplored 
The present study investigated if a positively framed description of sustainable farming as opposed to positively framed descriptions of flavour, health benefits, or socially responsible farming, influences young highly educated consumers' liking and willingness to pay for farmed salmon. Specifically, two differently prepared Atlantic salmon (Salmo salar) products, fresh raw salmon and hot smoked salmon, were tested, and the messages/labels tested in this study were focused on the production methods of the feed (aquafeed) used in salmon farms. The focus on aquafeed, rather than on other production variables, was selected to represent one of the highest recurrent costs of aquaculture practices and has attracted some criticisms with respect to its sustainability. For example, at the moment, the amount of fish from the ocean needed to feed farmed salmon can be seen as not sustainable. However, aquafeed has the capability of directly affecting all the parameters studied (including nutrition/health and flavour). In addition, feed companies are typically the largest players in the aquaculture production chain, and accordingly have a greater capability of intervention, R\&D investment, and marketing. A positive consumer perception of aquafeed will help the industry to further develop and sell sustainable fish products.

\section{Materials and Methods}

Regular consumers of salmon tasted and rated their liking and willingness to pay for two different types of salmon products; fresh raw salmon and hot smoked salmon. The four randomly assigned descriptive marketing type labels were focused either on sustainability, flavour, nutrition/health, or social responsibility (Table 1). Each combination of the type of salmon and labelling was presented once to each consumer. In addition, they tasted the two types of salmon without descriptive labelling. All participants tasted the fresh raw, as well as smoked, salmon in all label combinations, which resulted in 10 samples for each participant. After tasting all samples, participants rated the perceived importance of sustainability, flavour, nutrition/health, or social responsibility on food in general. In addition, they were asked how much they considered sustainability, flavour, nutrition/health and social responsibility when actually buying food in general or fish specifically.

Table 1. The four marketing descriptive labels used for the consumer taste test.

\begin{tabular}{ll}
\hline \multicolumn{1}{c}{ Label Type } & \multicolumn{1}{c}{ Description } \\
\hline Social responsibility & $\begin{array}{l}\text { This unique salmon has been farmed with a novel feed developed to maximise the social responsibility, and the overall } \\
\text { ethical quality, of the entire production cycle; ingredients used were preferentially locally produced and all produced } \\
\text { and purchased under fair trade conditions, greatly supporting local and regional communities by providing premium } \\
\text { prices to farmers, that guarantee safe working conditions and fair remuneration for their employees. }\end{array}$ \\
\hline Flavour & $\begin{array}{l}\text { This unique salmon has been farmed with a novel feed developed specifically towards improving the flavour and taste } \\
\text { of its fillet; the feed has been carefully formulated via also the expert support of high quality selected chefs, to } \\
\text { highlight fresh sea aroma of salmon fillet, improving its firmness, juiciness, brightness and brilliant colour, and making } \\
\text { this salmon perfectly delicious, rich, flavourful and succulent. }\end{array}$ \\
\hline Sustainability & $\begin{array}{l}\text { This unique salmon has been farmed with a novel feed developed specifically towards improving its overall } \\
\text { sustainability; only certified and sustainably sourced agricultural products and no wild caught marine products, have } \\
\text { been used to formulate this feed; with focus on the feed overall digestibility and nutrient bioavailability and resulting } \\
\text { in no nitrogen nor phosphorus wastes being released into the ocean and rivers. }\end{array}$ \\
\hline Nutrition/Health & $\begin{array}{l}\text { This unique salmon has been farmed with a novel feed developed specifically towards improving the nutritional } \\
\text { qualities of its fillet; a lean product, rich in protein of high biological value, packed with antioxidants, essential trace } \\
\text { elements and the entire suite of vitamins, and an abundance of beneficial long chain omega-3 fatty acids, making this } \\
\text { salmon the most nutritious and healthy of all superfoods. }\end{array}$ \\
\hline
\end{tabular}

The testing was conducted in computerised, partitioned sensory booths in the Centre for Advanced Sensory Science at Deakin University, and data was collected using Compusense Cloud as part of the Compusense Academic Consortium (Compusense Inc., Ontario, Canada. The study design and protocol was approved by the Deakin University Human Ethics Committee (HREC 2012-162); all consumers provided informed, written consent prior to study commencement. The consumers were asked to refrain from eating, drinking (except room temperature water), brushing teeth or chewing gum for one hour prior to testing.

Stimuli: The fresh Atlantic salmon was collected from a wholesaler the morning prior to the sensory tests (Clamms Seafood, Yarraville, Victoria, Australia). All fresh salmon originated from the 
same batch, same farm, and was harvested and processed the evening before. The hot smoked salmon was sourced by the same wholesaler and came from the same farm as the fresh salmon. The smoked salmon originating all from the same batch and were collected frozen on the morning prior to the sensory tests. Salmon products were offered to the consumers to taste in portions of $5 \mathrm{~g}$ at room temperature in clear medicine cups. In total, the participants tasted five fresh and five smoked pieces of salmon.

Participants: All consumers were students enrolled in an undergraduate degree at Deakin University and consumed fish at least once every month. Eight participants were excluded because they did not want to taste the salmon. A total of 119 participants (108 female, 11 male, $23 \pm 3.9 \mathrm{yrs}$ ) were included in the final analyses of the study.

Procedure: At the start of the test, consumers were told that they were going to taste sashimi (fresh raw salmon, hereafter referred to as Fresh) and hot smoked salmon (hereafter referred to as Smoked). They were also told the following: "Just to inform you, we have given you some more information about the fish you will be tasting". Consumers tasted four samples of Fresh and Smoked salmon to which a descriptive label was attached and a sample without labelling in a randomised order (see Table 1). In order to make sure the participants read the description without making them aware of the real purpose of the study, they were told: "in the interest of time could you please read the description while you are tasting, this will make the tasting and rating a bit quicker". After the five salmon samples were tasted, consumers waited one minute before another control and four samples with randomly assigned descriptive labels were presented. The design was balanced and randomised in such a way that all participants tasted all combinations of fish type and descriptive labels. The offering of Fresh and Smoked salmon was alternated. Consumers rinsed their mouth with water after tasting each piece of salmon.

Measurement of liking and willingness to pay: While tasting each sample consumers were asked to score on a $10 \mathrm{~cm}$ structured line scale how much they liked the salmon (hereafter referred to as "liking"). The lines were anchored with "not liked at all" $(-5 \mathrm{~cm})$ on the left side to "like very much" on the right side $(5 \mathrm{~cm})$, and neutral in the middle $(0 \mathrm{~cm})$. The line was separated by three evenly spread markers. After consumers rated liking they were asked how much they wanted to pay for the salmon they just tasted by showing the following text on screen: "regular salmon sells for about $\$ 10$ per $250 \mathrm{~g}$. How much would you be willing to pay for $250 \mathrm{~g}$ of the salmon you just tasted?" Underneath this question, they were presented with a $10 \mathrm{~cm}$ structured line scale with the following evenly spread markers $\$ 8, \$ 9, \$ 10, \$ 11, \$ 12$. Participants could mark the line anywhere between $\$ 8$ and $\$ 12$. The reference price was deliberately provided to make sure that all participants had the same reference price point in mind when answering the question.

Measurement attitudes and behaviour: After all fish samples were tasted, participants were asked the following questions. "You are about to buy fish. What does make you decide to buy a particular fish?" Participants were presented with 4 statements (e.g., the fish is tasty; the way the fish is farmed is good for the environment; the way the fish is farmed is good for the community and farms; Consuming the fish will be good for your health) and were asked to rank these statements from most to least decisive. In addition, they were asked the following questions: "How important is it to you that the fish you buy (a) gives fair wages to farmers? (b) is produced with sustainable methods? (c) is tasty? (d) is good for your health? Participants were asked to score these statements on a 5 points scale (e.g., 1 = not important at all; 2 = not important; 3 = between not important and important; 4 = important; and $5=$ very important. This score is referred to as the "importancy score"). Next, they were asked to rate how often they considered Sustainability, Flavour, Health/nutrition, or Social responsibility at the point of purchase when buying fish $(1=$ never, $2=$ sometimes, $3=$ often, $4=$ always $)$. Next, consumers were asked how often (i.e., less than once a month, 1-3 times per month, once per week, twice per week, 3-4 times per week, 5-6 times per week, every day) they consumed raw, steamed/grilled/baked, fried and/or canned fish. Basic demographic data (i.e., age, gender) were collected at the end of the questionnaire. 
Two separate linear univariate models were used to investigate the role of the salmon type and label type on (1) liking and (2) willingness to pay. More specifically, a general linear univariate model with "descriptive labelling" and "Salmon type" as fixed factors and "liking" as the dependent variable was applied to investigate the influence of "descriptive labelling" and "salmon type" on "liking". A second linear model with "descriptive labelling" and "Salmon type" as fixed factors and the "price willing to pay for salmon" as the dependent variable was applied to investigate the influence of "descriptive labelling" and "salmon type" on "willingness to pay". Post-hoc analyses with Bonferroni correction were carried out to identify if the "sustainability label" influenced liking and willingness to pay in a different way as the remaining labels did. In order to take into account that the data was not independent (e.g., all participants rated all samples on liking and willingness to pay), participants' ID was included as a random factor but not as variable. $p$-values $<0.05$ were considered statistically significant.

To investigate the importance of sustainability, flavour, health/nutrition, and social responsibility, the importancy score of sustainability was compared against the importancy score of flavour, health/nutrition, and social responsibility by using a Wilcoxon non-parametric test for two related samples. In which, not important at all $=1$, not important $=2$, between not important and important $=3$, important $=4$, very important $=5$ ). A similar analysis was conducted to investigate if sustainability was more often considered when buying fish than flavour, health/nutrition, or social responsibility.

Sustainability-focused consumers were identified as those who reported often or always to consider "sustainability" when buying food. Taste focused consumers were identified as those who reported always to consider "taste" when buying food. Health-focused consumers were identified as those who reported always to consider "health" when buying food. When consumers reported to always consider taste and health when buying food, they were counted as both taste focused and health-focused consumers. It is important to point out that taste and health focus was used as a way to look at the sample set, rather than a comparison of taste versus health-focused consumers. All statistical procedures were performed with IBM SPSS statistics Version 22, 64-bit edition.

\section{Results}

\subsection{Subject Characteristics}

The majority of consumers were female (91\%) and had at least completed year 12 of secondary school (Table 2). As shown in Table 3, fish was most frequently consumed (more than once a month) as steamed/grilled/ baked and/or canned fish. Raw and fried were the least popular preparation methods. Virtually all consumers reported that flavour and/or health were important to very important when it came to food choices. Sustainability and social responsibility were the least important aspects of food $(p<0.0001)$. This is also a reflection of how often participants considered sustainability when buying fish. That is, $4.2 \%$ of participants "always" considered sustainability when buying fish. This was significantly lower than the frequency at which they considered flavour, health/nutrition, or social responsibility when buying fish $(p<0.0001)$ (see Tables $3-5)$.

Table 2. The demographic characteristics (mean \pm sem) of participants in the consumer taste test.

\begin{tabular}{cccc}
\hline & Overall & Health Focused $(\boldsymbol{n}=\mathbf{5 9})^{\mathbf{1}}$ & Taste Focused $(\boldsymbol{n}=\mathbf{6 8})$ \\
\hline Age $(\mathrm{yrs})$ & $23 \pm 3.9$ & $23 \pm 3.4$ & $23 \pm 3.4$ \\
Male & $9 \%(11)$ & $5.1 \%(3)$ & $6 \%(4)$ \\
Female & $91 \%(108)$ & $95 \%(56)$ & $94 \%(64)$ \\
\hline
\end{tabular}

1 Taste focused consumers were identified as those who reported to always consider "taste" when buying food. Health-focused consumers were identified as those who reported to always consider "health" when buying food. When consumers reported to always consider taste and health when buying food, they were counted as both taste focused and health-focused consumers. Taste and health focus was used as a way to look at the sample set, rather than a comparison of taste versus health-focused consumers. 
Table 3. The participants' frequency of fish and fish product consumption.

\begin{tabular}{lccccccc}
\hline & $<$ 1/Month & 1-3/Month & 1/Week & 2/Week & 3-4/Week & 5-6/Week & Every Day \\
\hline Raw (including sushi) & $47.9 \%$ & $29.4 \%$ & $10.9 \%$ & $5.9 \%$ & $5 \%$ & $1 \%$ & $1 \%$ \\
Steamed, grilled or baked & $14.3 \%$ & $37.8 \%$ & $26.9 \%$ & $13.4 \%$ & $6.7 \%$ & $1 \%$ & - \\
Fried (including take away) & $63.9 \%$ & $27.7 \%$ & $6.7 \%$ & $1.7 \%$ & - & - & - \\
Canned (salmon, tuna, & $34.5 \%$ & $23.5 \%$ & $21.0 \%$ & $13.4 \%$ & $7.6 \%$ & - & - \\
sardines, etc.) & & & & & & & \\
\hline
\end{tabular}

Table 4. The percentage of participants who judged sustainability, flavour, health/nutrition, or social responsibility as not important at all to very important.

\begin{tabular}{lcccc}
\hline & Sustainability & Flavour & Health/Nutrition & Social Responsibility \\
\hline Not important at all & - & - & - & $0.8 \%$ \\
Not important & $5.0 \%$ & - & - & $5.0 \%$ \\
Between not important and important & $34.5 \%$ & $5.0 \%$ & $3.4 \%$ & $32.8 \%$ \\
important & $47.9 \%$ & $41.2 \%$ & $46.2 \%$ & $51.3 \%$ \\
Very important & $12.6 \%$ & $53.8 \%$ & $50.4 \%$ & $10.1 \%$ \\
\hline \multicolumn{2}{c}{${ }^{1}$ Sustainability was significantly less important than flavour and health/nutrition $p<0.0001}$.
\end{tabular}

Table 5. The percentage of participants who considered sustainability, flavour, health/nutrition, or social responsibility when buying fish (point of purchase).

\begin{tabular}{ccccc}
\hline & Sustainability $^{\mathbf{1}}$ & Flavour & Health/Nutrition & Social Responsibility \\
\hline Never & $26.9 \%$ & $4.2 \%$ & $1.7 \%$ & $24.4 \%$ \\
Sometimes & $45.4 \%$ & $5.0 \%$ & $9.2 \%$ & $36.1 \%$ \\
Often & $23.5 \%$ & $23.5 \%$ & $42.9 \%$ & $29.4 \%$ \\
Always & $4.2 \%$ & $67.2 \%$ & $46.2 \%$ & $10.1 \%$ \\
\hline
\end{tabular}

${ }^{1}$ Sustainability was significantly less considered when buying fish than flavour, health/nutrition, and social responsibility $p<0.0001$.

\subsection{Influence of Descriptive Labelling on Liking and Willingness to Pay}

The general linear univariate model showed a main effect of type of salmon offered on liking $(p<0.05)$ and a borderline significant main effect of descriptive labels on liking $(p=0.07)$. Fresh salmon was liked less than Smoked salmon (Fresh: $-1.7 \mathrm{~cm} \pm 0.13 \mathrm{~cm}$ vs. Smoked: $1.4 \mathrm{~cm} \pm 0.14 \mathrm{~cm})(p<0.001)$. When investigating the influence of labels on each salmon type individually, it was found that descriptive labelling about Sustainability $(-1.1 \mathrm{~cm} \pm 0.37 \mathrm{~cm}, p=0.04)$, Flavour $(-0.95 \mathrm{~cm} \pm 0.37 \mathrm{~cm}$, $p=0.01)$, and Health/nutrition $(-1.3 \mathrm{~cm} \pm 0.37 \mathrm{~cm}, p=0.01)$ significantly increased consumers' liking for Fresh salmon compared to the same fish without labels $(-1.8 \mathrm{~cm} \pm 0.37 \mathrm{~mm})$. No such difference was found between the Social responsibility label $(-1.1 \mathrm{~cm} \pm 0.35 \mathrm{~cm})$ and the fish without labels $(p=0.2)$. Post hoc analyses revealed no significant difference between the Sustainability descriptive label and the remaining descriptive labels (Figure 1). Descriptive labelling did not influence consumers' liking for Smoked salmon (no labels: $1.3 \mathrm{~cm} \pm 0.36 \mathrm{~cm}$ vs. Smoked labelled: $1.6 \mathrm{~cm} \pm 0.07 \mathrm{~mm}$ ) $(p=0.60)$ (Figure 1). 


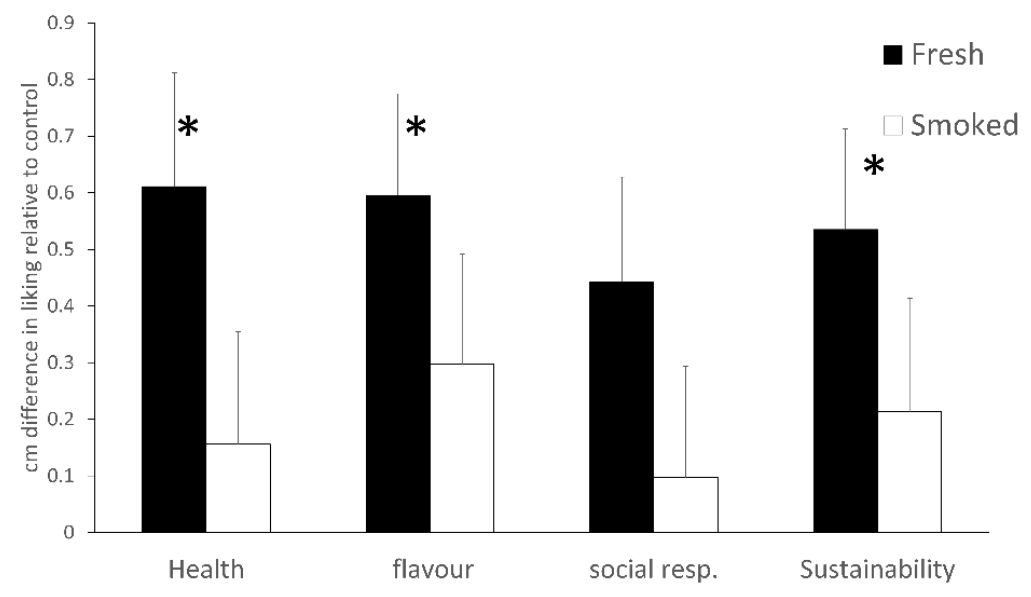

Figure 1. The relative difference $(\mathrm{cm})$ (mean \pm sem) in liking compared to fish without labels (control), shown for different descriptive labels (i.e., health, taste, social responsibility and sustainability). Positive (maximum $=+10$ or negative difference (maximum $=-10$ ) indicates that fish with a descriptive label is more or less liked respectively, than the control fish. * indicates a significant difference $(p<0.05)$ compared to the same salmon without a descriptive label.

The general linear univariate model showed a main effect of the type of salmon offered $(p<0.001)$ and a main effect of the descriptive labels $(p<0.001)$ on the willingness to pay. Participants were willing to pay more for Fresh and Smoked Salmon with descriptive labels (Fresh: $\$ 9.3 \pm \$ 0.003$; Smoked: $\$ 10.1 \pm \$ 0.003)$, than for the same Salmons without such labels (Fresh: $\$ 9.0 \pm \$ 0.06$; Smoked: $\$ 9.8 \pm \$ 0.08)(p<0.001)$. No significant differences were observed between the different descriptive labels (Figure 2). Liking and buying intent were, for all labels and fish types, strongly correlated $r=0.80, p<0.001$.

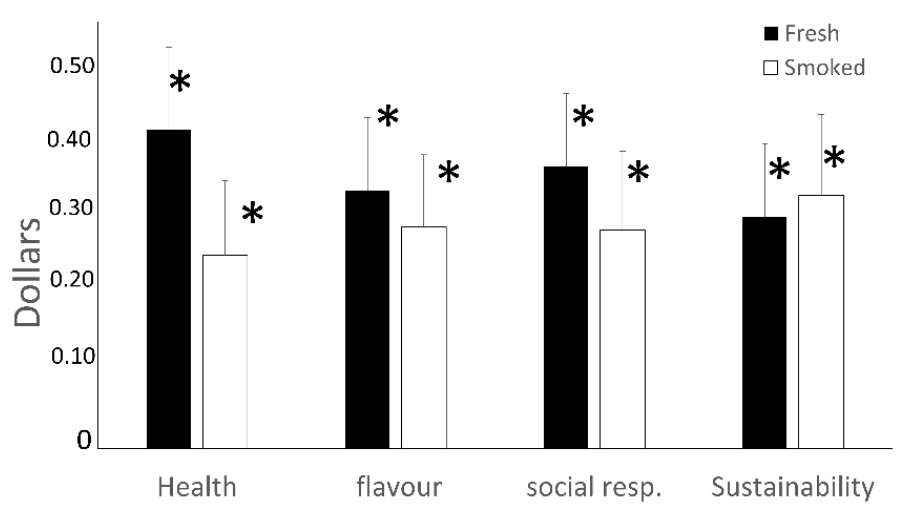

Figure 2. The difference in $\$$ amount (mean \pm sem) that participants are willing to pay more for $250 \mathrm{~g}$ of salmon (e.g., fresh, smoked) with different labels (i.e., health, taste, social responsibility and sustainability) compared to control fish without labels $(\mathrm{cm})$. * indicates a significant difference $(p<0.05)$ compared to the same salmon without a descriptive label.

\subsection{Sustainability, Health, and Taste Focused Consumers}

Seventy-one consumers (60\%) were classified as sustainability-focused consumers. The influence of sustainability labelling on fish liking and buying intentions of sustainably focused consumers was not different from the influence of these labels on none-sustainable focused consumers.

When only selecting consumers who highly focused on taste, it was found that the flavour descriptive label increased liking of fresh salmon (control: $-1.8 \pm 0.4$ vs. flavour label: $-1.0 \pm 0.4$ ) $(p<0.05)$. The remaining descriptive labels did not influence liking. The health-focused consumers 
were, however, more willing to pay more for any of the fresh salmon with descriptive labels, than for the same salmon without such labels. Although health-focused consumers' liking of the hot smoked salmon was not influenced by any of the descriptive labels, they were willing to pay more for smoked salmon which carried either the sustainability or the social responsibility descriptive label compared to the same salmon without such labels $(p<0.05)$.

Descriptive labels did not influence taste focused consumers' liking of fresh nor smoked salmon. However, taste focused consumers were willing to pay more for the fresh salmon with a flavour description, than for the same fresh salmon without a descriptive label. Such difference was not found for the nutrition/health, social responsibility or sustainability label.

\section{Discussion}

The present study demonstrated that descriptive labels, including those focused on sustainability, can increase the liking and the amount that young highly educated consumers want to pay for salmon. However, descriptive labelling about sustainable fish feed as such did not increase the liking and "willingness to pay" more than labels focused on health and taste. This was even the case for those consumers who thought sustainability was very important. The influence of descriptive labelling depends on consumers' liking of the product and consumers' focus on taste and health. To our knowledge, this is the first study that investigated the influence of a variety of descriptive labelling (including sustainability) on the experienced liking of fish during consumption. The results can be explained and should be interpreted relative to, the positive halo effect descriptive labelling has on consumers.

The sustainability, flavour, and the nutrition/health descriptive label had the largest influence on participants' liking of fresh salmon, whereas the social responsibility description did not seem to influence liking. Yet, consumers were more likely to pay more for salmon when it carried a descriptive label about social responsibility. A recent study found that although consumers are willing to pay more for socially responsible labelled seafood, the influence is weaker compared to the influence of sustainability labelling of seafood on the willingness to pay [11]. Potentially, consumers did not see a logical link between social responsibility and the taste of fish. Therefore, the direct benefit (i.e., a tasty salmon) of socially responsible fish is less prominent compared to the direct benefit of fish, which is labelled as flavoursome and/or nutritious. Previous research suggests that the links between healthy and tasty, and flavour description and tasty are rather salient for consumers [36].

Although the sustainability label increased the liking of fresh salmon, a similar influence was not found for hot smoked salmon. Potentially sustainability labels have more influence on products which are moderately liked, rather than those which, without the presence of a descriptive label, are already highly liked. This can partly be explained by a ceiling effect; recall that all hot smoked salmon was very well liked. Furthermore, descriptive labelling did increase the price consumers were willing to pay for hot smoked salmon. This suggests that the descriptive labels had some positive effect on the evaluation of smoked salmon. Nevertheless, the strong positive correlation between taste liking and willingness to pay suggests that taste is likely to be a major contributor to the amount of money consumers want to pay for salmon. It needs, however, to be noted that in the present study, the willingness to pay was always measured after participants tasted the salmon. Therefore, the increase in willingness to pay can be a result of the labels participants saw, as well as the taste they experienced.

Grouping consumers based on their health and taste focus is relevant as shown by the present study. Taste focused consumers place more emphasis on taste than non-taste focused consumers, which can explain why only the flavour descriptive label was able to increase the price these taste focused consumers were willing to pay for salmon. With this in mind, it is particularly interesting that those who were focused on sustainability did not react differently to the sustainability description compared to those who were less focused on sustainability. This suggests that the increase in liking and willingness to pay is likely a result of a general effect of a positive descriptive label, rather than a specific effect of a sustainability description. In general, the participants in the present research showed far 
more interest in flavour and health of food than in sustainability. This is important information for the fish industry. Especially because the participants we tested are, in general, interested in sustainability, but relative to flavour and health it seems to be less important.

It has previously been found that product labelling can influence consumers' willingness to buy seafood [37]. What sets the present study apart from previous studies is that consumers actually tasted the fish rather than reporting what they thought the fish would taste like. The combination of market and sensory research (e.g., sensory marketing) is an approach which has gained attention and popularity in the past 15 years [38,39]. It is now well understood that external product cues can influence sensory perception and that the combination of sensory inputs needs to be in congruence with the marketing message. Like in the present study, these effects are usually small. However, due to the advances in food production and product development, differences between competitor products are often very small. Small but significant changes in liking, by using sensory marketing, can make a large difference in how a product performs on the market [38].

There are limitations which need to be taken into consideration when interpreting the results. This study was specifically focused on young highly educated, mainly female, adults. The reasoning behind this is that these consumers are more likely to be interested in sustainability [32-34,40]. If sustainability labelling has any effect on liking, it should at least have an influence on this select sample and it did to a certain extent. However, the sustainability label failed to be different compared to either a health or flavour focused label. In addition, at least for the participants in the present study, sustainability is not seen as important as health or flavour. This suggests that those working in the fish industry should at least temper their expectations of the potential attraction sustainability labelling has on young educated consumers. Having said that, the present study has been focused on a very select sample and follow up studies should be conducted with a sample of a more general population. Lastly, it is important to acknowledge that the present study only measured liking and not consumption per se. However, it has been repeatedly suggested that liking strongly correlates with consumption [41].

Author Contributions: Conceptualization, D.G.L., G.M.T. and R.K.; Methodology, D.G.L., G.M.T. and R.K.; Formal Analysis, D.G.L. and R.K.; Resources, R.K. and G.M.T.; Data Curation, D.G.L. and U.W.; Writing-Original Draft Preparation, D.G.L.; Writing-Review \& Editing, D.G.L., R.K., G.M.T. and U.W.; Funding Acquisition, R.K. and G.T.

Funding: This research was partly funded by Ridley Agriproducts, via the Deakin Ridley Aquaculture Research Initiative.

Acknowledgments: The authors express their gratitude to Roy Palmer for technical and logistic support for the sourcing of the fish products used in the present study.

Conflicts of Interest: The authors declare no conflict of interest. The founding sponsors had no role in the design of the study; in the collection, analyses, or interpretation of data; in the writing of the manuscript, and in the decision to publish the results.

\section{References}

1. Australian Government Department of Health and Ageing. Food for Health, Dietary Guidelines for Australians, A Guide to Healthy Eating; NHMRC: Canberra, Australia, 2005.

2. U.S. Department of Health and Human Services. Dietary Guidelines for Americans 2015-2020, 8th ed.; USDA: Washington, DC, USA, 2015.

3. Grant, R.; Guest, J.; Bilgin, J.; Morris, M.; Garg, M.; Pearce, R. Suboptimal Omega-3 levels in Australian adoscents. Int. J. Child Health Nutr. 2013, 2, 309-315.

4. Meyer, B. Australians are not Meeting the Recommended Intakes for Omega-3 Long Chain Polyunsaturated Fatty Acids: Results of an Analysis from the 2011-2012 National Nutrition and Physical Activity Survey. Nutrients 2016, 8, 111. [CrossRef] [PubMed]

5. Institute of Medicine and National Research Council. Annex 1: dietary recommendations for fish consumption. In A Framework for Assessing Effects of the Food System; Nesheim, M.C., Yih, O.M., Eds.; The National Academies Press: Washington, DC, USA, 2015.

6. Merino, G.; Barange, M.; Blanchard, J.L.; Harle, J.; Holmes, R.; Allen, I.; Allison, E.H.; Badjeck, M.C.; Dulvy, N.K.; Holt, J.; et al. Can marine fisheries and aquaculture meet fish demand from a growing human population in a changing climate? Glob. Environ. Chang. 2012, 22, 795-806. [CrossRef] 
7. Jennings, S.; Stentiford, G.D.; Leocadio, A.M.; Jeffery, K.R.; Metcalfe, J.D.; Katsiadaki, I.; Auchterlonie, N.A.; Mangi, S.C.; Pinnegar, J.K.; Ellis, T.; et al. Aquatic food security: Insights into challenges and solutions from an analysis of interactions between fisheries, aquaculture, food safety, human health, fish and human welfare, economy and environment. Fish Fish. 2016, 17, 893-938. [CrossRef]

8. Gopal, T.K.S.; Boopendranath, M.R. Seafood ecolabelling. Fish. Technol. 2013, 50, 1-10.

9. Jaffry, S.; Pickerin, H.G.Y.; Whitmarsh, D.; Wattage, P. Consumer choices for quality and sustainability labelled seafood products in the UK. Food Policy 2004, 29, 215-228. [CrossRef]

10. Brecard, D.; Lucas, S.; Pichot, N.; Salladarre, F. Consumer Preferences for Eco, Health and Fair Trade Labels. An Application to Seafood Product in France. J. Agric. Food Ind. Organ. 2012, 10. [CrossRef]

11. McClenachan, L.; Dissanayake, S.T.M.; Chen, X. Fair trade fish: Consumer support for broader seafood sustainability. Fish Fish. 2016, 17, 825-838. [CrossRef]

12. Johnston, R.J.; Wessells, C.R.; Donath, H.; Asche, F. Measuring consumer preferences for eco-labelled seafood. An international comparison. J. Agric. Resour. Econ. 2001, 26, 20-39.

13. Hallstein, E.; Villas-Boas, S.B. Can household consumers save the wild fish? Lessons from a sustainable seafood advisory. J. Environ. Econ. Manag. 2013, 66, 52-71. [CrossRef]

14. Kreider, C.R.; Gempesaw, C.M.; Bacon, J.R.; Toensmeyer, U.C.; Groff, A.J. An analysis of consumer perceptions of frehs fish and seafood in the Delmarva region. J. Food Distrib. 1993, 4, 37-48.

15. Carlucci, D.; Nocella, G.; De Devitiis, B.; Viscecchia, R.; Bimbo, F.; Nardone, G. Consumer purchasing behaviour towards fish and seafood products. Patterns and insights from a sample of international studies. Appetite 2014, 84, 212-227. [CrossRef] [PubMed]

16. Fernqvist, F.; Ekelund, L. Credence and the effect on consumer liking of food-A review. Food Qual. Prefer. 2014, 32, 340-353. [CrossRef]

17. Wansink, B.; Ittersum van, K.; Painter, J.E. How descriptive food names bias sensory perception in restaurants. Food Qual. Prefer. 2005, 16, 393-400. [CrossRef]

18. Wansink, B.; Payne, C.R.; North, J. Fine as North Dakota wine: Sensory expectations and the intake of companion foods. Physiol. Behav. 2007, 90, 712-716. [CrossRef] [PubMed]

19. Liem, D.G.; Bolhuis, D.P.; Hu, X.; Keast, R.S.J. Short communication: Influence of labeling on Australian and Chinese consumers' liking of milk with short (pasteurized) and long (UHT) shelf life. J. Dairy Sci. 2016, 99, 1747-1754. [CrossRef] [PubMed]

20. Wansink, B.; Park, S.B. Sensory suggestiveness and labelling: Do soy labels bias taste. J. Sens. Stud. 2002, 17, 483-491. [CrossRef]

21. Liem, D.G.; Toraman-Aydin, N.; Zandstra, E.H. Effects of health labels on expected and actual taste perception of soup. Food Qual. Prefer. 2012, 25, 192-197. [CrossRef]

22. Liem, D.G.; Miremadi, F.; Zandsra, E.H.; Keast, R.S.J. Health labelling can influence taste perception and use of table salt for reduced-sodium products. Public Health Nutr. 2012, 15, 2340-2347. [CrossRef] [PubMed]

23. Aaron, J.I.; Mela, D.J.; Evans, R.E. The influence of attitudes, beliefs and label information on perception of reduced-fat spreads. Appetite 1994, 22, 25-37. [CrossRef] [PubMed]

24. Wansink, B.; Just, D.R.; Payne, C.R.; Klinger, M.Z. Attractive names sustain increased vegetable intake in schools. Prev. Med. 2012, 55, 330-332. [CrossRef] [PubMed]

25. Didier, T.; Lucie, S. Measuring consumer's willingness to pay for organic and Fair Trade products. Int. J. Consum. Stud. 2008, 32, 479-490. [CrossRef]

26. Rousseau, S. The role of organic and fair trade labels when choosing chocolate. Food Qual. Prefer. 2015, 44, 92-100. [CrossRef]

27. Aoki, K.; Akai, K.; Ujiie, K. A choice experiment to compare preferences for rice in Thailand and Japan: The impact of origin, sustainability, and taste. Food Qual. Prefer. 2017, 56, 274-284. [CrossRef]

28. Tully, S.M.; Winer, R.S. The Role of the Beneficiary in Willingness to Pay for SociallyResponsible Products: A Meta-analysisStephanie. J. Retail. 2014, 2, 255-274. [CrossRef]

29. Visschers, V.H.M.; Siegrist, M. Does better for the environment mean less tasty? Offering more climate-friendly meals is good for the environment and customer satisfaction. Appetite 2015, 95, 475-483. [CrossRef] [PubMed]

30. Cho, Y.-N. Different Shades of Green Consciousness: The Interplay of Sustainability Labeling and Environmental Impact on Product Evaluations. J. Bus. Ethics 2015, 128, 73-82. [CrossRef]

31. Van Dam, Y.; De Jonge, J. The positive side of negative labelling. J. Consum. Policy 2015, 38, 19-38. [CrossRef] 
32. Kagawa, F. Dissonance in students' perceptions of sustainable development and sustainability Implications for curriculum change. Int. J. Sustain. High. Educ. 2007, 8, 317-338. [CrossRef]

33. Richard Emanuel, J.N.A. College students' perceptions of campus sustainability. Int. J. Sustain. High. Educ. 2011, 12, 79-92. [CrossRef]

34. Gilg, A.; Barr, S.; Ford, N. Green consumption or sustainable lifestyles? Identifying the sustainable consumer. Futures 2005, 37, 481-504. [CrossRef]

35. Carrero, I.; Redondo, R.; Fabra, M.E. Who is behind the sustainable purchase? The sustainable consumer profile in grocery shopping in Spain. Int. J. Consum. Stud. 2016, 40, 643-651. [CrossRef]

36. Van Kleef, E.; van Trijp, H.C.M.; Luning, P. Functional foods: Health claim-food product compatibility and the impact of health claim framing on consumer evaluation. Appetite 2005, 44, 299-308. [CrossRef] [PubMed]

37. Disdier, A.-C.; Marette, S. How do consumers in developed countries value the environment and workers' social rights in developing countries? Food Policy 2012, 37, 1-11. [CrossRef]

38. Krishna, A. An integrative review of sensory marketing: Engaging the senses to affect perception, judgment and behavior. J. Consum. Psychol. 2012, 22, 332-351. [CrossRef]

39. Liem, D.G. Sensory and Marketing-partners for life. Food N. Z. 2016, 16, 24-25.

40. Verbeke, W. Functional foods: Consumer willingness to compromise on taste for health. Food Qual. Prefer. 2005, 17, 126-131. [CrossRef]

41. Drewnowski, A.; Hann, C. Food preferences and reported frequencies of food consumption as predictors of current diet in young women. Am. J. Clin. Nutr. 1999, 70, 28-36. [CrossRef] [PubMed]

(C) 2018 by the authors. Licensee MDPI, Basel, Switzerland. This article is an open access article distributed under the terms and conditions of the Creative Commons Attribution (CC BY) license (http://creativecommons.org/licenses/by/4.0/). 